\title{
Understanding impacts and barriers to adoption of climate-smart agriculture (CSA) practices in North-western Nigerian drylands
}

Article

Accepted Version

Jellason, N. P., Conway, J. S. and Baines, R. N. (2021) Understanding impacts and barriers to adoption of climatesmart agriculture (CSA) practices in North-western Nigerian drylands. Journal of Agricultural Education and Extension, 27 (1). pp. 55-72. ISSN 1750-8622 doi:

https://doi.org/10.1080/1389224X.2020.1793787 Available at https://centaur.reading.ac.uk/91857/

It is advisable to refer to the publisher's version if you intend to cite from the work. See Guidance on citing.

Published version at: https://www.tandfonline.com/doi/full/10.1080/1389224X.2020.1793787

To link to this article DOI: http://dx.doi.org/10.1080/1389224X.2020.1793787

Publisher: Taylor \& Francis

All outputs in CentAUR are protected by Intellectual Property Rights law, including copyright law. Copyright and IPR is retained by the creators or other copyright holders. Terms and conditions for use of this material are defined in the End User Agreement. 


\section{www.reading.ac.uk/centaur}

\section{CentAUR}

Central Archive at the University of Reading

Reading's research outputs online 


\begin{abstract}
Purpose: Empirical evidence suggests that climate-smart agriculture (CSA) practices will promote resilience against climate change. We explored location-specific CSA practices and strategies for adoption in two communities (Zango and Kofa) in the North-Western Nigerian drylands.
\end{abstract}

Design/methodology/approach: Mixed methods design was employed with thirty smallholders per community selected from a baseline study of 220 smallholders from the two study communities. Smallholders were engaged in a farmer participatory learning and action (PLA) on CSA adoption for resilience. Impacts of PLA were evaluated six months post-implementation and barriers for adoption explored.

Findings: Pre- and post-PLA training indicated a change in confidence to adopt some CSA practices. Both communities showed greater confidence $(p<0.05)$ related to solving climate-related problems and the use of fertiliser. Communities differed in relation to other factors: Kofa exhibited improved confidence (71.4\%) in solving water challenges while Zango showed greater confidence (76\%) in relation to solving environmental problems. We found gender-responsive CSA promote women participation in farming.

Practical implications: A deep understanding of the underlying reasoning behind nonadoption of CSA practices could support future climate resilience policies, and the lead-farmer extension model could reduce extension agent-farmer ratio.

Theoretical implications: Identification of climate-smart agriculture practices and their adoption confirms the benefit of participatory learning for transformation, in this case empowerment of smallholders, including women, to adapt to climate change in a wider sub-Saharan Africa context.

Originality/value: This study explores PLA application in supporting the uptake of CSA practices for resilience and advancement of lead-farmer extension for reducing extension agent-farmer ratio.

Keywords: Participatory learning and action (PLA); Extension; Smallholders; Climatesmart agriculture; Adaptation; Barriers. 


\section{Introduction}

Smallholders are responsible for producing most of the food consumed in sub-Saharan Africa (SSA) (FAO 2017) with 70\% being produced by women (AGRA 2014). Approximately 53\% of these smallholders are poor, and about $28 \%$ suffer from undernourishment. Many of these smallholders rely on rainfed agriculture, are climate dependent and suffer low crop yields (AGRA 2014). In addition, climate change and variability are part of the seasonal experiences of smallholders especially those resident in drylands who have evolved adaptation strategies to these uncertain and variable environments (Mortimore and Adams 2001). Despite this, it is suggested that collective community knowledge is limited to anticipating weather events that have previously been experienced but not the additional extremes that climate change is predicted to bring (Adger et al. 2011). Hence, planning by farmers for rainfall dependent agriculture will be based on the expectation of both poor and good rainfall (AGRA 2014).

Agriculture operates in a complex dynamic socio-ecological system with unpredictabilities including policy, economic and climatic uncertainties (Darnhofer 2010, 2014). Site specific climate-smart agriculture (CSA) practices will play a vital role in reducing the impact of climate change on food security, increase income of the most vulnerable population and enhance smallholders' resilience (FAO 2018, 2017). Publicly provided agricultural extension will likely support the uptake of technologies such as CSA (Aker 2011). Agricultural extension or advisory services are used to disseminate information (Lamontagne-Godwin et al. 2018). Numerous methods have been used, ranging from coercion, and law enforcement (Mukembo 2015), training and visits (T\&V) (Venkatesan 1997), community and commodity-based extension, farming systems research and extension (Roberts 1989) previously in a ‘top-down' fashion (Mukembo 2015). The cost of reaching these mostly dispersed and illiterate smallholders (Bamire, Fabiyi, and Manyong 2002) with 
less access to mass media in SSA has been on the increase (Amungwa 2018). Secondly, the impact of these top-down approaches in improving SSA agriculture are mixed (Aker 2011). Critics of top-down (external knowledge) approach argue that promoters package practices that do not consider ongoing (indigenous) innovations. This portrays a lack of respect for the intellect and creativity of local farmers (Matthews 2017, Mortimore and Adams 2001).

Participatory approaches were later introduced due to the shortcomings of the topdown extension to improve the welfare of farmers (Amungwa 2018). Approaches such as the farmer field schools were introduced initially in India and later spread to SSA (FAO 2016). This approach involved collaborative learning between researchers, and / or farmers and extensionists, sometimes through participatory learning and action (PLA) that leads to transformational change (Percy 2005, Amungwa 2018). PLA involves experiential learning by communities and critical reflection which leads to empowerment (Mezirow 1990, Freire 1972). The merits of PLA approaches to agricultural research that is 'demand-driven' (ground-up), and puts people at the centre of learning have been advocated in the literature (de Vente et al. 2016, Reed 2008, Chambers 2005, Cooke and Kothari 2001, Martin and Sherington 1997).

Critics of participatory approaches argue that while this approach aim to alter existing power imbalance in a family or community by empowering the less privileged, participation could reinforce power on the knowledge facilitator (expert) leading to more disempowerment of the deprived (Mohan 2001, Arnstein 1969). Another obvious criticism is the argument that participation fosters a binary and dichotomous notion of 'insidersoutsiders'; 'expert-local' knowledge and 'beneficiary-facilitator' (Kothari 2001, Chambers 2005). Also, participation can act as a means of obscuring 'top-down' approaches by development project sponsors which can act as 'rubber stamp' and thus validate special interests leading to bias (Cooke and Kothari 2001, Arnstein 1969). As such, external actors 
essentially usurp the autonomy of communities (Matthews 2017). Accordingly, this duality oversimplifies complex social dynamics in participatory development approaches, thereby concealing existing power imbalances (Kothari 2001).

Contrarily, participatory approaches will promote farming resilience if the process is properly designed according to a specific context and stakeholder interests (de Vente et al. 2016, Mapfumo et al. 2013, Reed 2008, Martin and Sherington 1997). For instance, de Vente et al. (2016) argued that the success of the participatory process depends on adequate representation of stakeholders, structured facilitation in a professional way to balance power relations among participants; empowerment of participants and supply of information for the adaptation decision-making process.

Past studies on the adoption of agricultural innovations erroneously assume adoption to be a linear process without acknowledging its complexity (Douthwaite and Hoffecker 2017). Often, the role of the beneficiaries in the process of adoption, development, and demonstration of an innovation is neglected (Meijer et al. 2015) which constitute barriers to adoption (FAO 2017). The urgency of climate change will require proactive responses that are time-bound (Long, Blok, and Coninx 2015). It is anticipated that overcoming the barriers to the adoption of CSA practices will enhance the resilience of smallholders to climate change, and at the same time promote food security (Kpadonou et al. 2017). Certainly, the adoption of improved science-based practices have been shown to be more successful if participants are fully engaged in the process where they can share their experiences and develop action plans (Mapfumo et al. 2013, de Vente et al. 2016).

CSA identification, valuation and prioritisation have been the bane of CSA adoption in SSA (Andrieu et al. 2017). CSA innovations will support adaptation and agricultural productivity in affected areas, which will be externally driven through training in climate- 
smart practices adoption (Long, Blok, and Coninx 2015) that merges community knowledge and science. CSA promotion and capacity development for adoption requires change in existing agricultural practices, behaviours and strategies of farmers (FAO 2017). Extension services will play a key role in this regard so that the decision-making process of farmers will be adapted towards being resilient (FAO 2017). Any factors that inhibit recognition of change in climate or the adoption of new practices to combat the change will constitute a barrier to adaptation. The existence of barriers has slowed the adoption of improved resilience practices in marginal areas of sub-Saharan Africa (Cordingley et al. 2015). These barriers are further reflected by the lack of capacity of local farming communities, poor access to improved technologies, poor information and institutional support for climate change adaptation (Mapfumo et al. 2013).

Barriers comprise institutional, socio-economic and cultural. These include financial capital (Burbi, Baines, and Conway 2016); lack of information, poor land tenure, market failure and infrastructural deficits (Altieri and Nicholls 2012); appropriateness of the innovation to the end-user, labour requirement and access to external inputs, and use of crop residues for animal feeding (Giller et al. 2009). The process of CSA adoption could also constitute a barrier. According to Rogers (2003), the choice to adopt an innovation comprises five stages- knowledge, persuasion, decision, implementation and confirmation. However, the assumed linearity of this process is contested (Glover et al. 2019). For example, a recent study of indigenous innovation in rural Niger found local farmers adopt innovations through a consensus process where they confer with each other as part of the decision-making process (Matthews 2017). However, the consensual process of decision-making by smallholders is argued to be biased towards an outsider as exemplified in the Participatory Rural Appraisals (PRAs) paradigm (Chambers 2005). 
Niles, Brown, and Dynes (2016) suggested that location-specific case studies are suitable for assessing determinants of adoption for a given situation. The heterogeneous nature of farms in SSA make bespoke interventions to solve environmental challenges more appropriate, compared to a generalised approach. Therefore, making technologies userfriendly and involving the potential users in the process of development aids uptake (Mekoya et al. 2008). In other words, it is not about the adoption of new practices but adaptation which requires an interactive process of participatory learning and action (PLA).

Few studies have been conducted on barriers to adoption of CSA in the context of smallholder farming in sub-Saharan Africa (SSA) (Antwi-Agyei, Dougill, and Stringer 2015). Most studies on barriers to climate change adaptation are in the context of developed countries (Long, Blok, and Coninx 2015). Even among the few SSA studies, few have considered the impact of CSA practices adoption in the context of West African smallholders (Tarchiani et al. 2017). For climate change adaptation to be effective, there is a need to overcome these barriers and to deliver the CSA practices in a participatory way with the users as equal stakeholders (Tarchiani et al. 2017). Hence, this study will attempt to explore the impact of participatory approaches in managing the effect of climate change in Kofa and Zango communities in North-Western Nigeria. We will also empirically examine the underlying reasoning behind adoption or the barriers for adoption of CSA to support farmers' adaptation decision-making processes and contribute to the debate on the merits of participatory approaches. 


\section{Materials and methods}

\section{Study site}

This study was carried out between March to May 2016 and October to November 2016 with smallholder farmers in two communities (Zango and Kofa) in North-Western Nigeria (Figure 1). The choice of study sites is appropriate to understand the impacts, reasons for adoption and barriers to adoption of CSA by smallholder farmers to manage extreme weather events. Smallholder farmers are responsible for producing about $80 \%$ of the food consumed in Africa and mostly suffer food insecurity and risk of losing their livelihoods from disasters due to smaller land, water stress, poor soil fertility, rainfall variability with less access to improved seeds (FAO 2017, Wani et al. 2009). This is true for Nigeria due to its vulnerability, poor awareness of climate change, inadequate water supply for agriculture, weak institutions, poverty and the low capacity of smallholders to adapt (Jellason et al. 2019). In terms of the two communities, Zango generally experiences lower rainfall (591 $\mathrm{mm})$, and higher temperatures compared to Kofa $(835 \mathrm{~mm})$.

\section{(Inset Figure 1 here).}

\section{Selection of the participants and design of the CSA Training and PLA}

We selected thirty (30) lead farmers per community with the help of extension agents from an initial baseline study. Lead farmers are farmers selected to train other farmers in a "farmerto-farmer" extension model (Franzel, Sinja, and Simpson 2014). Selected farmers of different age and gender (Table 2) were engaged in CSA PLA for climate change adaptation that included the farmers developing their own cropping action plans. This is in line with putting the farmers at the centre of learning through experimentation, empowerment and valuing their technical knowledge (Chambers 1993). And if CSA practices are not adopted, to 
understand the barriers for adoption. PLA in this context refers to the process of identifying and demonstrating good climate-smart practices facilitated by the researchers in collaboration with the participants and extension agents using a feedback mechanism.

Selection of climate-smart agriculture (CSA) practices

We selected CSA practices based on a previous farmer baseline study and a literature review of scientific evidence behind CSA usage by smallholders in similar drylands (Wani et al. 2009, Georgis, Dejene, and Malo 2010, Sambalino and Steenbergen 2012). This was followed by a stakeholder confirmation by researchers and practitioners using Delphi studies reported elsewhere. Validation of context-specific CSA is necessary to avoid misconception of the criteria for "climate smartness" of practices (Neufeldt et al. 2013). Practices reviewed included water, land, and soil fertility management practices to inform the participatory learning and action process. We shared the list of the CSA (Table 1) with farmers in a focus group discussion (FGD) workshop and explained their scientific underpinnings. We included bio-intensive garden preparation to mainstream gender and increase women participation, livelihood and as a resilience strategy (FAO 2018). 
(Insert Table 1 here)

Training and PLA objectives

The objectives of the training and farmer learning and action were to develop skills of participants (Martin and Sherington 1997) and promote the integration and increased adoption of site specific CSA practices for resilience (FAO 2018).

Selection of PLA options, ranking and field demonstration

Sub-optimal consequences from the adoption of innovations could result from lack of participation of end-users in the process of designing the practices (de Vente et al. 2016, Reed 2008). Hence, participants together with an extensionist were involved in selecting the most appropriate CSA practices and the best form of learning suitable to their conditions to guide PLA activities (Table 2).

(Insert Table 2 here)

Based on the preferred CSA practices and PLA options selected by the participants, we implemented field demonstration, training and action planning and then reflected upon what worked well and what did not. The cycle was repeated. This was dialogic as farmers, extension agents and researchers came together to identify and agree on the appropriate methods to be implemented (Percy 2005).

\section{Evaluation of training and PLA}

Semi-structured questionnaires were administered to the participants- pre-learning and six months post-learning at harvest stage to evaluate the efficacy of CSA after PLA (supplemental material appendix 1). A separate semi-structured questionnaire was 
developed to appraise the level of adoption, reasons, and barriers for adoption of the practices (supplemental appendix 2).

Pre- and post-PLA questionnaire for data collection

We used both focus group discussion (for selection of PLA methods) and developed semistructured questionnaires for this study which consisted of two sections, demographics and general information on current farming situations and practices. Demographic questions included age, gender, educational level (Table 3) and name for easy tracking of participants at the post-PLA evaluation stage. The general information section consisted of twenty questions (see supplemental material appendix 1). The questionnaires were then piloted, and poorly framed questions were corrected. Only 21 farmers in Kofa and 24 in Zango were tracked at the post-adoption appraisal stage; the attrition rates recorded were due to participant sickness, inability to locate participants at the time of assessment. 


\section{Data analysis}

Qualitative data were analysed thematically while quantitative data were analysed using IBM SPSS, version 23. We carried out a non-parametric test (Wilcoxon Signed Rank Test) to compare results before and after PLA. We employed Wilcoxon Signed Rank Test due to the small sample size and lack of stringent requirements of normality with parametric techniques (Pallant 2013). This complementary quantitative analysis method was employed for triangulation as participatory approaches alone could introduce bias through group composition of participants or a few dominant group members (Goebel 1998). 


\section{Results}

Participants selected from the two communities for the PLA represented different age categories, gender, and educational levels (Table 3). About 53\% of the participants for Kofa fall between $18-20$ years but only about $37 \%$ for Zango fall under the same age category. In terms of education, about $43 \%$ and $40 \%$ had no formal education in Zango and Kofa, respectively. In terms of gender, Zango had 30\% female, $70 \%$ male while Kofa had $23 \%$ female and $77 \%$ male. 
(Insert Table 3 here.) 


\section{PLA outcomes}

Only participants captured in the pre- and post-PLA program were used for this analysis. We employed a quantitative appraisal of the PLA due to time limit of Ph.D. field work. The quantitative test revealed a statistically significant improvements in 'solving environmental problems' affecting farming following participation in the PLA (90.5\%-Kofa; 76\%-Zango). For Kofa $\mathrm{z}=-2.27, p<0.05$, with a medium effect size $(r=0.35)$; and for Zango $\mathrm{z}=-3.70, p$ $<0.05$, with a large effect size $(r=0.52)$. The median score on the 'Solving Environmental Problem Scale' for Kofa was constant pre- and post-PLA $(M d=4)$. Whereas the median score for Zango increased from pre-PLA $(M d=3)$ to post-PLA $(M d=5)$.

In terms of 'Yield differences' and 'confidence about solving drought challenges', Kofa participants, showed significant improvements pre- and post-PLA for crop yield differences (100\%-Kofa; 80\%-Zango), $\mathrm{z}=-3.40, \mathrm{p}<0.05$, with a large effect size $(0.52)$ compared to Zango; Median score for crop yield increased from pre-PLA $(\mathrm{Md}=4)$ to postPLA $(M d=5)$ meaning PLA was useful for improving yield and solving drought challenges. For 'confidence about solving drought challenges', $\mathrm{z}=-3.80, \mathrm{p}<0.05$, with a large effect size (0.59). Median score for 'confidence to solve drought challenges' increased from pre- $(\mathrm{Md}=$ 2) to post-PLA $(\mathrm{Md}=4)$ signifying that PLA improved the ability of participants to tackle future drought challenges (71.4\%-Kofa; 52\%-Zango). Other practices that showed significant differences after the PLA program in the two communities are marked with asterisks (*) (Table 4). 
(Insert Table 4 here) 


\section{Farmer engagement on adoption and barriers to adoption}

\section{Adoption and underlying reasons}

Results from the post-PLA appraisal show different levels of adoption (fully, partially, or not adopted) of the various practices such as improved seed varieties, crop rotation, mulching and cover cropping (Figures 2 and 3). Improved seed varieties were highly valued and adopted in the two communities (however, a few improved seeds were given to each of the participants as an appreciation for participating in the research which may have biased their opinions on this). The role of incentives in dramatically increasing adoption of innovations has previously been reported (Cordingley et al. 2015, Rogers 2003). Other practices highly adopted in Zango were: 'no burning of crop residue', 'crop rotation' and 'mulching and cover cropping' all of which have become increasingly important methods of maintaining soil productivity and structure (Knowler and Bradshaw 2007). Reasons behind the adoption of 'no burning of crop residues' included: 'because it was well understood', 'to control soil erosion', 'source of livestock feed', 'to protect soil cover', and participants 'not used to burning crop residue'. For mulching, reasons for adoption included: 'it suppresses weed', 'enhances fertility', 'based on advice given from training' and 'to conserve water'. For Kofa community, mulching was highly adopted to maintain residues for water retention in furrows, and for fertility enhancement. On the other hand, 'no burning of residue' was highly adopted due to the utility of crop residue as livestock feed, for water retention in furrows to avoid crops drying up, and participants not being used to burning residues was another reason.

\section{(Insert Figures 2 and 3 here)}




\section{Barriers to adoption of CSA practices}

Several barriers were responsible for poor uptake of some of the practices in the two communities which were grouped thematically with the percentage of non-adoption highlighted. These barriers were categorised into environmental, physical, institutional, economic, psychsocial, and cultural and whether they were external or internal and their interactions (Figure 4). To understand these reasons, households were probed on why they did not adopt the practices after PLA. Practices with a non-adoption rate above $50 \%$ for the two communities were set as a benchmark for this study and barriers to adoption are presented (Tables 5 and 6). Coincidentally, similar practices were not adopted in the two communities, albeit, at different rates.

\section{(Insert Figure 4 here)}


(Insert Tables 5 and 6 here) 


\section{Discussion}

In this study, we explored impacts and barriers to adoption of CSA practices in both Zango and Kofa communities. Results corroborate other studies that point to the benefits of a well designed participatory adoption process (de Vente et al. 2016). PLA had positive impacts on increasing the confidence levels of farming households to solve their climate change related challenges compared to before PLA in Zango while in Kofa, no impacts were recorded. Researchers acted to facilitate the PLA process and to allow the farmers to take charge of their learning and action thereby tackling issues of power dynamics associated with top-down research approaches. Consequently, farmers developed their action plans based on their farming systems and the climate change-related challenge faced. Learning activities were separated between women and men as most women in north-western Nigerian communities do not mix freely with men due to cultural reasons. We encouraged women to maintain high intensity gardens in their backyards as source of cooking essentials. The need to mainstream gender in the project design of such participatory research is key to avoiding women marginalisation and to increase impact due to their participation (Kristjanson et al. 2017).

We observed that differences exist in some of the practices adopted in the two communities and these are suggestive of the adverse environmental conditions experienced in Zango (driest community) compared to Kofa with less adverse environmental conditions. Hence, we propose PLA to be encouraged to manage climate change as it can be tailored to the specific challenges of each community and due to its positive impact. An additional explanation for the differences in the benefit of PLA in the two communities, however, could relate to Kofa having relatively more access to extension information through television compared to Zango (supplemental material appendix 3B); thus, suggesting that absence of external extension could result in poor adoption of CSA practices. Currently, government 
extension agent to farmer ratio is wide in Nigeria thereby making extension information difficult to reach many farmers (Adesoji 2009). Hence, the lead-farmer extension introduced in this study will be relevant in increasing extension coverage. Farmers learning from each other will mean that best practices will easily be adopted based on evidence and other conditions remaining favourable. Adoption of appropriate fertiliser application practices (using precision method) was high in the two communities even though no fertiliser was given; this practice was found to help reduce the total amount and the cost of fertilisers used which constitute a high-cost input to farming. Findings from this study show mulching was adopted based on the PLA and advice given. This agrees with Kpadonou et al. (2017) who argued that training was an important determinant of adoption of soil and water conservation technologies in the West African Sahel.

We demonstrated that barriers exist and operate at different levels which are complementary (Figure 4) supporting an earlier study by Meijer et al. (2015) who argued that both extrinsic and intrinsic factors are responsible for the uptake of innovation. Hence, one cannot be considered without the other. High adoption of 'no burning of crop residue' is not surprising as leaving crop residue in the field has previously been reported as an essential sustainable soil and crop management practice, and a key element of conservation agriculture (Giller et al. 2009). However, the practice is limited in conservation agriculture due to alternative uses of crop residue (Giller et al. 2009) such as for animal feed. Lack of knowledge as barrier to adoption was also found, making it consistent with Mekoya et al. (2008) who suggested that farmers' ability to understand and adapt a technology to their local context facilitates long-term adoption. These barriers were thematically categorised into cultural, economic, environmental, psychosocial, physical, and institutional barriers for better analysis. Cultural barriers recorded include lack of familiarity with a practice. Findings from this study further revealed that some farmers did not uptake new practices because they were 
accustomed to their old practices. Investing more in human capital of farmers through PLA will aid the adoption of innovation based on skills gap identified in the study communities which should be a target for climate change adaptation policy.

Respondents also reported lack of capital as a barrier to the uptake of practices including water harvesting and garden preparation in both communities. This portrays lack of capacity and a serious setback to climate change adaptation in the two communities thereby necessitating some sort of external support. Other studies have reported lack of credit as a key constraint to the adoption of innovation for adaptation to climate change in the Savanna zone of Nigeria (De Haen 1997) and drylands of northern Ghana (Antwi-Agyei, Dougill, and Stringer 2015). Adoption of new technology requires a financial capital outlay, particularly if new equipment is a prerequisite (Knowler and Bradshaw 2007). Lack of water harvesting structures was a key barrier to the adoption of water harvesting practices in the two communities. However, to overcome this barrier, a need exists in finding means of financing the acquisition of water harvesting structures. This barrier aligns with economic barriers (Figure 4) to innovation uptake as lack of capital hinders the acquisition of these structures. Like Mapfumo et al. (2013), poor institutional support has been found as a barrier to adaptation thereby increasing vulnerability. Though lack of market was found as a barrier to adoption of innovation in Africa (Antwi-Agyei, Dougill, and Stringer 2015), it is not stated in this study. This is presumably due to the less involvement of the participating households in cash crop production. Overcoming these barriers through public investment will improve the adoption of these innovations and make farming a viable venture in those communities.

As mixed quantitative-qualitative methods are important tools for understanding farming systems (Kristjanson et al. 2017), this study utilised quantitative appraisal of the PLA activities 'before and after' in order to quantify the benefits of CSA adoption. While 
participatory approaches were used in understanding indepth reasons for adoption and barriers. PLA approaches improved farmers' confidence in adopting CSA practices to enhance their resilience to climate change. Although quantitative assessments provide some important reminders, the small sample size could limit the value of quantitative assessments in this study. Hence, future studies with small sample sizes could benefit more from the integration of indepth participatory appraisal approaches.

Drawing on CSA adoption literature, this study contributes to the body of knowledge on barriers to adoption. The main contribution is in extending knowledge on the impact of PLA on CSA practices adoption for climate change management. Continuous investment in participatory approaches are needed to ensure context specific CSA practices are adopted, research beneficiaries actively engage in the transformative processes, and having their voices heard. These approaches would be highly beneficial to SSA smallholders due to their literacy rate so that they would be more adaptive in a continuously changing environment. 


\section{Conclusion}

The benefits of participatory innovation adoption in building the confidence of farmers to solve climate change-related challenges were demonstrated. Non-parametric quantitative appraisal was employed to explore relationships between adoption and non adoption for small samples while qualitative appraisal helped in examining the motivations for the actions taken. This is based on the evidence of impact pre- and post-PLA as the PLA exercises improved some key variables such as confidence to manage climate change in the two communities. Interestingly, there were no significant improvements in some practices after the training although this was not unexpected as participating farming households indicated lack of interest in some of the practices displayed and were not willing to try new ideas. This is against a backdrop of a plethora of barriers that hinder the adoption of innovation for adaptation. It is hoped that the findings from this work would contribute to a deeper understanding of processes of CSA uptake and the reasoning behind non-adoption to inform future policy on SSA drylands resilience management and to mainstream participatory climate change adaptation to future agricultural development. Further research should consider long-term post-adoption appraisal using more participatory approaches as the current study was based on six months quantitative post-adoption assessment due to the time limit of a Ph.D. study.

\section{Disclosure statement}

No potential conflict of interest was reported by the authors.

Funding: This research did not receive any specific grant from funding agencies in the public, commercial, or not-for-profit sectors. 


\section{Reference}

Adesoji, S. A. 2009. "Assessment of Agricultural Extension Agents' Marketing-Related Services: Implications for Policy Makers in Ekiti State, Nigeria." Journal of Agricultural \& Food Information 10 (4):334-347. doi: 10.1080/10496500903245420.

Adger, W. Neil, Katrina Brown, Donald R. Nelson, Fikret Berkes, Hallie Eakin, Carl Folke, Kathleen Galvin, Lance Gunderson, Marisa Goulden, Karen O'Brien, Jack Ruitenbeek, and Emma L. Tompkins. 2011. "Resilience implications of policy responses to climate change." Wiley Interdisciplinary Reviews: Climate Change 2 (5):757-766. doi: 10.1002/wcc.133.

AGRA. 2014. Africa Agriculture Status Report: Climate Change and Smallholder Agriculture in SubSaharan Africa. Nairobi, Kenya: The Alliance for a Green Revolution in Africa (AGRA).

Aker, Jenny C. 2011. "Dial " $A$ " for agriculture: a review of information and communication technologies for agricultural extension in developing countries." Agricultural Economics 42 (6):631-647. doi: 10.1111/j.1574-0862.2011.00545.x.

Altieri, Miguel A., and C. I. Nicholls. 2012. "Agroecology Scaling Up for Food Sovereignty and Resiliency." In Sustainable Agriculture Reviews: Volume 11, edited by Eric Lichtfouse, 1-29. Dordrecht: Springer Netherlands.

Amungwa, F.A. 2018. "Appraisal of Innovations in Agricultural Extension and Advisory Services in Cameroon " Journal of Advancements in Plant Science 1 (206).

Andrieu, N., B. Sogoba, R. Zougmore, F. Howland, O. Samake, O. Bonilla-Findji, M. Lizarazo, A. Nowak, C. Dembele, and C. Corner-Dolloff. 2017. "Prioritizing investments for climate-smart agriculture: Lessons learned from Mali." Agricultural Systems 154:13-24. doi: https://doi.org/10.1016/j.agsy.2017.02.008.

Antwi-Agyei, Philip, Andrew J. Dougill, and Lindsay C. Stringer. 2015. "Barriers to climate change adaptation: evidence from northeast Ghana in the context of a systematic literature review." Climate and Development 7 (4):297-309. doi: 10.1080/17565529.2014.951013.

Arnstein, Sherry R. 1969. "A Ladder Of Citizen Participation." Journal of the American Institute of Planners 35 (4):216-224. doi: 10.1080/01944366908977225.

Bamire, A. S., Y. L. Fabiyi, and V. M. Manyong. 2002. "Adoption pattern of fertiliser technology among farmers in the ecological zones of south-western Nigeria: a Tobit analysis." Australian Journal of Agricultural Research 53 (8):901-910. doi: https://doi.org/10.1071/AR01095.

Burbi, Sara, R. N. Baines, and J. S. Conway. 2016. "Achieving successful farmer engagement on greenhouse gas emission mitigation." International Journal of Agricultural Sustainability:118. doi: 10.1080/14735903.2016.1152062.

Chambers, Robert. 1993. Challenging the Professions: F/rontiers for rural development. London: Intermediate Technology Publications Ltd.

Chambers, Robert. 2005. Ideas for Development. London: Earthscan.

Cooke, Bill, and Uma Kothari, eds. 2001. Participation: The new tyranny. London: Zed Books.

Cordingley, Justine E., Katherine A. Snyder, Judith Rosendahl, Fred Kizito, and Deborah Bossio. 2015. "Thinking outside the plot: addressing low adoption of sustainable land management in subSaharan Africa." Current Opinion in Environmental Sustainability 15 (Supplement C):35-40. doi: https://doi.org/10.1016/i.cosust.2015.07.010.

Darnhofer, Ika. 2010. "Strategies of family farms to strengthen their resilience." Environmental Policy and Governance 20 (4):212-222. doi: 10.1002/eet.547.

Darnhofer, Ika. 2014. "Resilience and why it matters for farm management." European Review of Agricultural Economics 41 (3):461-484. doi: 10.1093/erae/jbu012.

De Haen, Hartwig. 1997. "Environmental Consequences of Agricultural Growth in Developing Countries." In Sustainability, Growth, and Poverty Alleviation: A Policy and Agroecological Perspective, edited by Stephen A. Vosti and Thomas Reardon. The Johns Hopkins University Press. 
de Vente, Joris, Mark S. Reed, Lindsay C. Stringer, Sandra Valente, and Jens Newig. 2016. "How does the context and design of participatory decision making processes affect their outcomes? Evidence from sustainable land management in global drylands." Ecology and Society 21 (2). doi: 10.5751/ES-08053-210224.

Douthwaite, Boru, and Elizabeth Hoffecker. 2017. "Towards a complexity-aware theory of change for participatory research programs working within agricultural innovation systems."

Agricultural Systems 155 (Supplement C):88-102. doi: https://doi.org/10.1016/j.agsy.2017.04.002.

FAO. 2016. Farmer Field School Guidance Document: Planning for qaulity programmes. Rome: Food and Agriculture Organization of the United Nations.

FAO. 2017. Climate-Smart Agriculture Sourcebook Summary. Rome.

FAO. 2018. Climate-Smart Case studies 2018: Successful approaches from different regions. Rome: Food and Agriculture Organisation of the United Nations.

Franzel, Steven, Judith Sinja, and Brent Simpson. 2014. Farmer-to-farmer extension in Kenya: the perspectives of organizations using the approach.

Freire, Paulo. 1972. Pedagogy of the Oppressed. Middlesex, New Jersey: Penguin Books.

Georgis, Kidane, Alemneh Dejene, and Meshack Malo. 2010. Agricultural based Livelihood Systems in drylands in the Context of Climate Change: Inventory of Adaptation practices and Technologies of Ethiopia. Rome.

Giller, Ken E., Ernst Witter, Marc Corbeels, and Pablo Tittonell. 2009. "Conservation agriculture and smallholder farming in Africa: The heretics' view." Field Crops Research 114 (1):23-34. doi: https://doi.org/10.1016/j.fcr.2009.06.017.

Glover, Dominic, James Sumberg, Giel Ton, Jens Andersson, and Lone Badstue. 2019. "Rethinking technological change in smallholder agriculture." Outlook on Agriculture 48 (3):169-180. doi: 10.1177/0030727019864978.

Goebel, Allison. 1998. "Process, Perception and Power: Notes from 'Participatory' Research in a Zimbabwean Resettlement Area." Development and Change 29 (2):277-305. doi: 10.1111/1467-7660.00079.

Jellason, P. Nugun, N. Richard Baines, S. John Conway, and C. Chukwuma Ogbaga. 2019. "Climate Change Perceptions and Attitudes to Smallholder Adaptation in Northwestern Nigerian Drylands." Social Sciences 8 (2). doi: 10.3390/socsci8020031.

Knowler, Duncan, and Ben Bradshaw. 2007. "Farmers' adoption of conservation agriculture: A review and synthesis of recent research." Food Policy 32 (1):25-48. doi: http://dx.doi.org/10.1016/i.foodpol.2006.01.003.

Kothari, Uma. 2001. "Power, Knowledge and Social Control in Participatory Development." In Participation: The New Tyranny?, edited by Bill Cooke and Uma Kothari, 139-152. London: Zed Books.

Kpadonou, Rivaldo A. Baba, Tom Owiyo, Bruno Barbier, Fatima Denton, Franck Rutabingwa, and Andre Kiema. 2017. "Advancing climate-smart-agriculture in developing drylands: Joint analysis of the adoption of multiple on-farm soil and water conservation technologies in West African Sahel." Land Use Policy 61:196-207. doi: http://dx.doi.org/10.1016/i.landusepol.2016.10.050.

Kristjanson, Patricia, Elizabeth Bryan, Quinn Bernier, Jennifer Twyman, Ruth Meinzen-Dick, Caitlin Kieran, Claudia Ringler, Christine Jost, and Cheryl Doss. 2017. "Addressing gender in agricultural research for development in the face of a changing climate: where are we and where should we be going?" International Journal of Agricultural Sustainability 15 (5):482500. doi: 10.1080/14735903.2017.1336411.

Lamontagne-Godwin, J., F. E. Williams, N. Aslam, S. Cardey, P. Dorward, and M. Almas. 2018. "Gender differences in use and preferences of agricultural information sources in Pakistan." The Journal of Agricultural Education and Extension 24 (5):419-434. doi: 10.1080/1389224X.2018.1491870. 
Long, Thomas B., Vincent Blok, and Ingrid Coninx. 2015. "Barriers to the adoption and diffusion of technological innovations for climate-smart agriculture in Europe: evidence from Netherlands, France, Switzerland and Italy." Journal of Cleaner Production:1-13.

Mapfumo, Paul, Samuel Adjei-Nsiah, Florence Mtambanengwe, Regis Chikowo, and Ken E. Giller. 2013. "Participatory action research (PAR) as an entry point for supporting climate change adaptation by smallholder farmers in Africa." Environmental Development 5:6-22. doi: http://dx.doi.org/10.1016/j.envdev.2012.11.001.

Martin, Adrienne, and John Sherington. 1997. "Participatory research methods-Implementation, effectiveness and institutional context." Agricultural Systems 55 (2):195-216. doi: https://doi.org/10.1016/S0308-521X(97)00007-3.

Matthews, Joel R. 2017. "Understanding Indigenous Innovation in Rural West Africa: Challenges to Diffusion of Innovations Theory and Current Social Innovation Practice." Journal of Human Development and Capabilities 18 (2):223-238. doi: 10.1080/19452829.2016.1270917.

Meijer, Seline S., Delia Catacutan, Oluyede C. Ajayi, Gudeta W. Sileshi, and Maarten Nieuwenhuis. 2015. "The role of knowledge, attitudes and perceptions in the uptake of agricultural and agroforestry innovations among smallholder farmers in sub-Saharan Africa." International Journal of Agricultural Sustainability 13 (1):40-54. doi: 10.1080/14735903.2014.912493.

Mekoya, Abebe, Simon J. Oosting, Salvador Fernandez-Rivera, and Akke J. Van der Zijpp. 2008. "Farmers' perceptions about exotic multipurpose fodder trees and constraints to their adoption." Agroforestry Systems 73 (2):141-153. doi: 10.1007/s10457-007-9102-5.

Mezirow, J. 1990. Fostering Critical Reflection in Adulthood: A guide to Transformative and Emancipatory Learning. San Francisco, California: Jossey Bass Wiley.

Mohan, Giles. 2001. "Beyond Participation: Strategies for Deeper Empowerment." In Participation: The New Tyranny?, edited by Bill Cooke and Uma Kothari, 153-167. London: Zed Books.

Mortimore, Michael J., and William M. Adams. 2001. "Farmer adaptation, change and 'crisis' in the Sahel." Global Environmental Change 11 (1):49-57. doi: http://dx.doi.org/10.1016/S09593780(00)00044-3.

Mukembo, Stephen. 2015. "Agricultural Extension in Sub-Saharan Africa During and After Its Colonial Era: The Case of Zimbabwe, Uganda, and Kenya." Journal of International Agricultural and Extension Education Volume 22:50-68. doi: 10.5191/jiaee.2015.22304.

Neufeldt, Henry, Molly Jahn, Bruce M. Campbell, John R. Beddington, Fabrice DeClerck, Alessandro De Pinto, Jay Gulledge, Jonathan Hellin, Mario Herrero, Andy Jarvis, David LeZaks, Holger Meinke, Todd Rosenstock, Mary Scholes, Robert Scholes, Sonja Vermeulen, Eva Wollenberg, and Robert Zougmoré. 2013. "Beyond climate-smart agriculture: toward safe operating spaces for global food systems." Agriculture \& Food Security 2 (1):12. doi: 10.1186/20487010-2-12.

Niles, Meredith T., Margaret Brown, and Robyn Dynes. 2016. "Farmer's intended and actual adoption of climate change mitigation and adaptation strategies." Climatic Change 135 (2):277-295. doi: 10.1007/s10584-015-1558-0.

Pallant, Julie. 2013. SPSS Survival Manual: A step by step guide to data analysis using IBM SPSS. 5th ed. Berkshire: Open University Press.

Percy, Rachel. 2005. "The contribution of transformative learning theory to the practice of participatory research and extension: Theoretical reflections." Agriculture and Human Values 22 (2):127-136. doi: 10.1007/s10460-004-8273-1.

Reed, Mark S. 2008. "Stakeholder participation for environmental management: A literature review." Biological Conservation 141 (10):2417-2431. doi:

https://doi.org/10.1016/i.biocon.2008.07.014.

Roberts, Nigel. 1989. Agricultural Extension in Africa. A World Bank Symposium. Washington, D.C.: World Bank, Washington, D. C. .

Rogers, Everett M. 2003. Diffusion of Innovation. 5th ed. London: Free Press. 
Royer-Miller, Margo. 2010. "A Farmer's Mini-Handbook: Grow Biointensive Sustainable MiniFarming." Ecology Action, accessed 02/03/2017.

http://www.growbiointensive.org/PDF/FarmersHandbook.pdf.

Sambalino, Francesco, and Frank Steenbergen. 2012. Securing Water and Land in the Tana Basin: a resource book for water managers and practitioners.

Sharma, N. K., and Raman Singh. 2013. Agronomic Practices for Erosion Control. Vol. 01.

Tarchiani, Vieri, Federica Rossi, José Camacho, Robert Stefanski, Kodjenini Augustin Mian, Dominic Soami Pokperlaar, Hamidou Coulibaly, and Aïssatou Sitta Adamou. 2017. "Smallholder Farmers Facing Climate Change in West Africa: Decision-Making between Innovation and Tradition." Journal of Innovation Economics \& Management 24 (3):151-176.

Tilman, David, Kenneth G. Cassman, Pamela A. Matson, Rosamond Naylor, and Stephen Polasky. 2002. "Agricultural sustainability and intensive production practices." NATURE 418:671-677.

Venkatesan, V. 1997. "Agricultural extension in sub-Saharan Africa: Extension typologies and issues for the future." Knowledge, Technology \& Policy 9 (4):43-61. doi: 10.1007/BF02912436.

Wani, Suhas, T. K Sreedevi, J. Rockström, and Y. Ramakrishna. 2009. Rainfed Agriculture - Past Trends and Future Prospects. 


\section{Tables}

Table 1. Selected CSA and the scientific evidence underpinning them.

\begin{tabular}{|c|c|c|}
\hline Practice & Benefits & References \\
\hline Cover crop & $\begin{array}{l}\text {-Reduced nutrient leaching } \\
\text {-Increased yield }\end{array}$ & -(Tilman et al. 2002) \\
\hline Mulching & -Increased yield by $30 \%$ compared to without mulching. & $\begin{array}{l}\text {-(Georgis, Dejene, and Malo } \\
\text { 2010) }\end{array}$ \\
\hline Crop rotation & $\begin{array}{l}\text {-Maintains fertility and reduces soil erosion } \\
\text {-Conserves moisture. }\end{array}$ & $\begin{array}{l}\text { (Tilman et al. 2002) } \\
\text { (Sharma and Singh 2013) }\end{array}$ \\
\hline $\begin{array}{l}\text { Water harvesting } \\
\text { from } \\
\text { rooftops/small } \\
\text { scale irrigation. }\end{array}$ & -Yield 24,700 litres from a surface area of $100 \mathrm{~m}^{2}$ with a seasonal rainfall of $260 \mathrm{~mm}$. & $\begin{array}{l}-(\text { Sambalino } \\
\text { Steenbergen 2012) }\end{array}$ \\
\hline $\begin{array}{l}\text { Bio-intensive } \\
\text { garden preparation. }\end{array}$ & $\begin{array}{l}\text {-Builds soil fertility. } \\
\text {-Uses small area to produce high yields. } \\
\text {-Minimizes water, and organic fertiliser. } \\
\text {-Means of engaging women in farming. }\end{array}$ & (Royer-Miller 2010). \\
\hline Composting & $2,449 \mathrm{~kg} / \mathrm{ha}$ and 5,071 kg/ha were recorded in Machakos and Nyeri respectively & $\begin{array}{l}\text { (Sambalino and Steenbergen } \\
\text { 2012) }\end{array}$ \\
\hline $\begin{array}{l}\text { Appropriate } \\
\text { fertiliser } \\
\text { application. }\end{array}$ & $\begin{array}{l}\text {-Restore soil fertility } \\
\text {-Improved water productivity } \\
\text {-Reduced amount of fertiliser. }\end{array}$ & $\begin{array}{l}\text { (Tilman et al. 2002) } \\
\text { (Wani et al. 2009) }\end{array}$ \\
\hline
\end{tabular}


Table 2. Ranking best options preferred for the training and co-learning exercise.

\begin{tabular}{ll}
\hline Community & Preffered learning method \\
\hline Zango & Training and field demonstration $\left(1^{\text {st }}\right)$, farmer to farmer training $\left(2^{\text {nd }}\right)$, \\
& training and action plan $\left(3^{\text {rd }}\right)$. \\
Kofa & Farmer to farmer training $\left(1^{\text {st }}\right)$, training and field demonstration $\left(2^{\text {nd }}\right)$, \\
& innovation platforms $\left(3^{\text {rd }}\right)$. \\
\hline
\end{tabular}


Table 3. Demographics of training and co-learning participants

\begin{tabular}{lll}
\hline Demographic item & Zango-n=30 $(\boldsymbol{\%})$ & Kofa-n=30 $(\boldsymbol{\%})$ \\
\hline Gender & $21(70)$ & $23(76.7)$ \\
Male & $9(30)$ & $7(23.3)$ \\
Female & & \\
Age & $11(36.7)$ & $16(53.3)$ \\
$18-20$ & $4(13.3)$ & $4(13.3)$ \\
$21-40$ & $15(50.0)$ & $10(33.3)$ \\
$41 \&$ above & & \\
Education & $13(43.3)$ & $12(40.0)$ \\
No education & $1(3.3)$ & $9(30.0)$ \\
Primary & $5(16.7)$ & $4(13.3)$ \\
Secondary & $11(36.7)$ & $5(16.7)$ \\
Tertiary & & \\
& & \\
\hline
\end{tabular}


Table 4. Wilcoxon Signed Rank Test Kofa $(n=21)$ and Zango $(n=25) . r=z / \sqrt{ }$. where $n=($ cases $x 2)$.

\begin{tabular}{|c|c|c|c|c|c|c|c|}
\hline & & & Kofa & & & Zangc & \\
\hline S/no & Item & $\bar{Z}$ & $\mathrm{r}$ & $\begin{array}{l}\text { Sig. (2- } \\
\text { tailed) }\end{array}$ & $\bar{Z}$ & $\mathrm{r}$ & $\begin{array}{l}\text { Sig. (2- } \\
\text { tailed) }\end{array}$ \\
\hline 1. & Happy with current practices & -1.51 & 0.23 & 0.132 & -0.56 & 0.08 & 0.57 \\
\hline 2. & Happy with current yield & -3.40 & 0.52 & $0.001 *$ & -0.09 & 0.01 & 0.928 \\
\hline 3. & Confident you can solve environmental problem & -2.27 & 0.35 & $0.023^{*}$ & -3.70 & 0.52 & $0.000 *$ \\
\hline 4. & Do you need training to support your farming & -1.29 & 0.20 & 0.197 & -0.06 & 0.01 & 0.953 \\
\hline 5. & Do you feel confident to solve water and drought challenges & -3.80 & 0.59 & $0.000 *$ & -1.68 & 0.24 & 0.094 \\
\hline 6. & Do you feel confident to solve soil fertility challenges & -0.73 & 0.11 & 0.463 & -0.48 & 0.07 & 0.632 \\
\hline 7. & Do you think women have a role to play in food security & -1.86 & 0.29 & 0.063 & -1.18 & 0.17 & 0.239 \\
\hline 8. & Litres of herbicides used in total & -1.93 & 0.30 & 0.053 & -0.54 & 0.08 & 0.589 \\
\hline 9. & Bags of fertilisers used & -2.07 & 0.32 & $0.039^{*}$ & -2.01 & 0.28 & $0.044 *$ \\
\hline 10. & Bags of produce harvested & -2.12 & 0.33 & $0.034^{*}$ & -1.07 & 0.15 & 0.285 \\
\hline 11. & Cost of labour for tillage & -1.93 & 0.30 & 0.053 & -0.13 & 0.02 & 0.896 \\
\hline
\end{tabular}




\begin{tabular}{|c|c|c|c|c|c|c|c|}
\hline 12. & Cost of labour for weeding & -2.57 & 0.40 & $0.010^{*}$ & -0.44 & 0.06 & 0.660 \\
\hline 13. & Cost of labour for harvesting & -1.68 & 0.26 & 0.092 & -1.89 & 0.27 & 0.059 \\
\hline 14. & Time spent on clearing & -0.84 & 0.13 & 0.403 & -0.24 & 0.03 & 0.813 \\
\hline 15. & Time spent on tillage & -0.04 & 0.01 & 0.971 & -2.31 & 0.33 & $0.021 *$ \\
\hline 16. & Time spent on planting & -0.46 & 0.07 & 0.646 & -0.73 & 0.10 & 0.467 \\
\hline 17. & Time spent on weeding & -0.35 & 0.05 & 0.723 & -0.78 & 0.11 & 0.438 \\
\hline 18. & Time spent on harvesting & -3.15 & 0.49 & $0.002 *$ & -3.62 & 0.51 & $0.000 *$ \\
\hline
\end{tabular}

*significant difference $\leq 0.05$. 
Table 5. Practices with the highest non-adoption in Kofa $(n=21)$ and barriers.

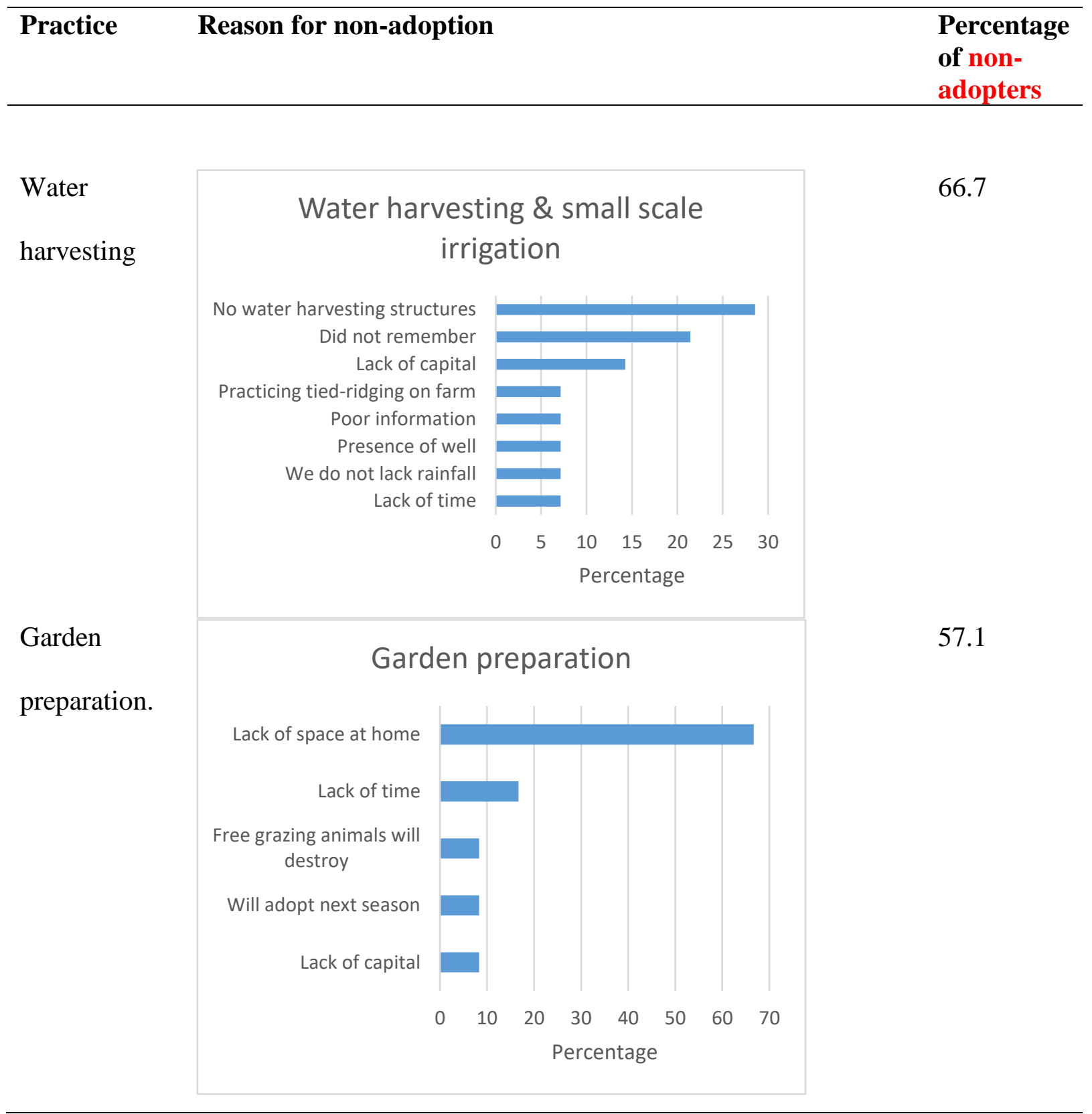


Table 6. Practices with the highest non-adoption in Zango $(n=24)$ and barriers.

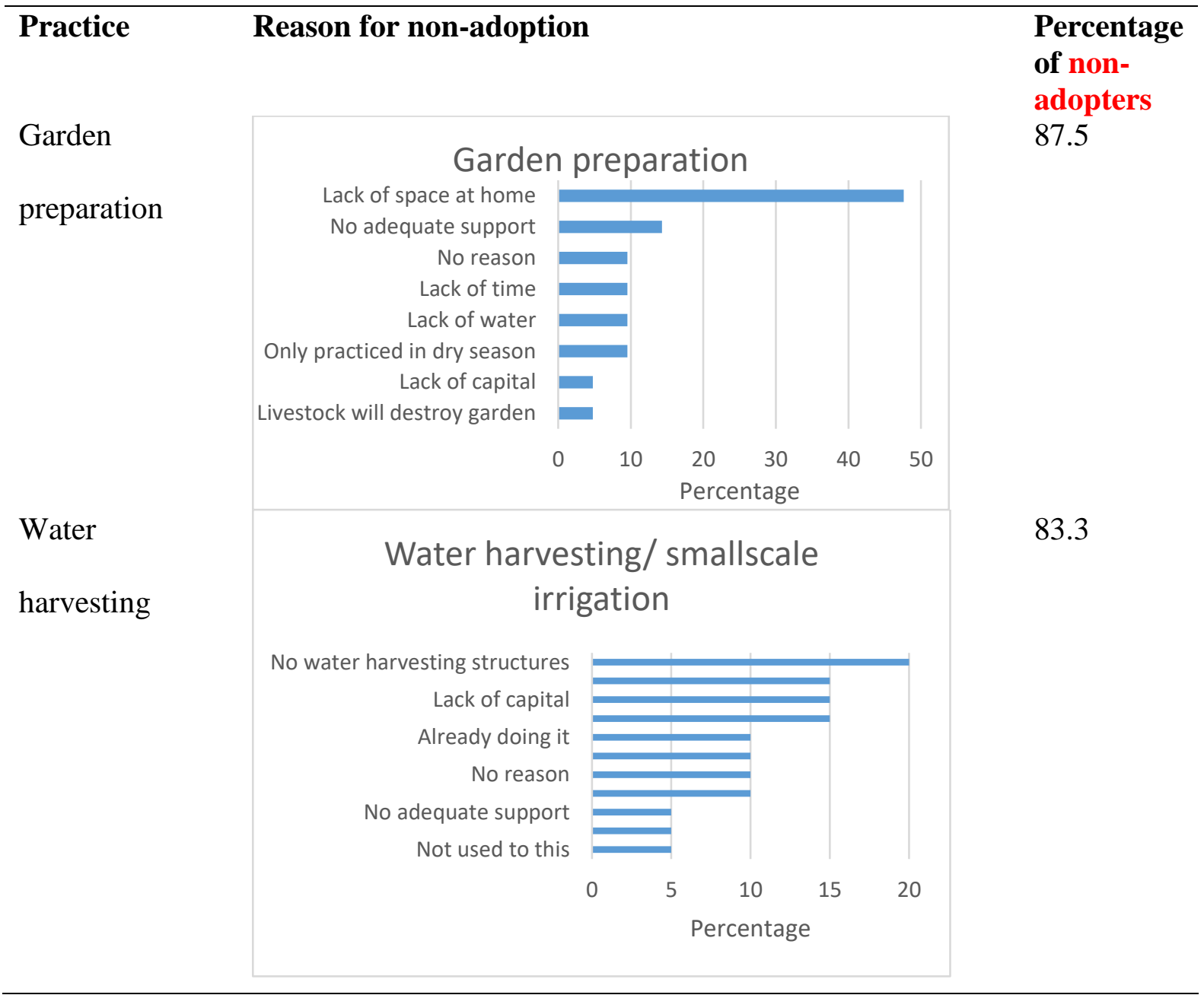




\section{Figures}

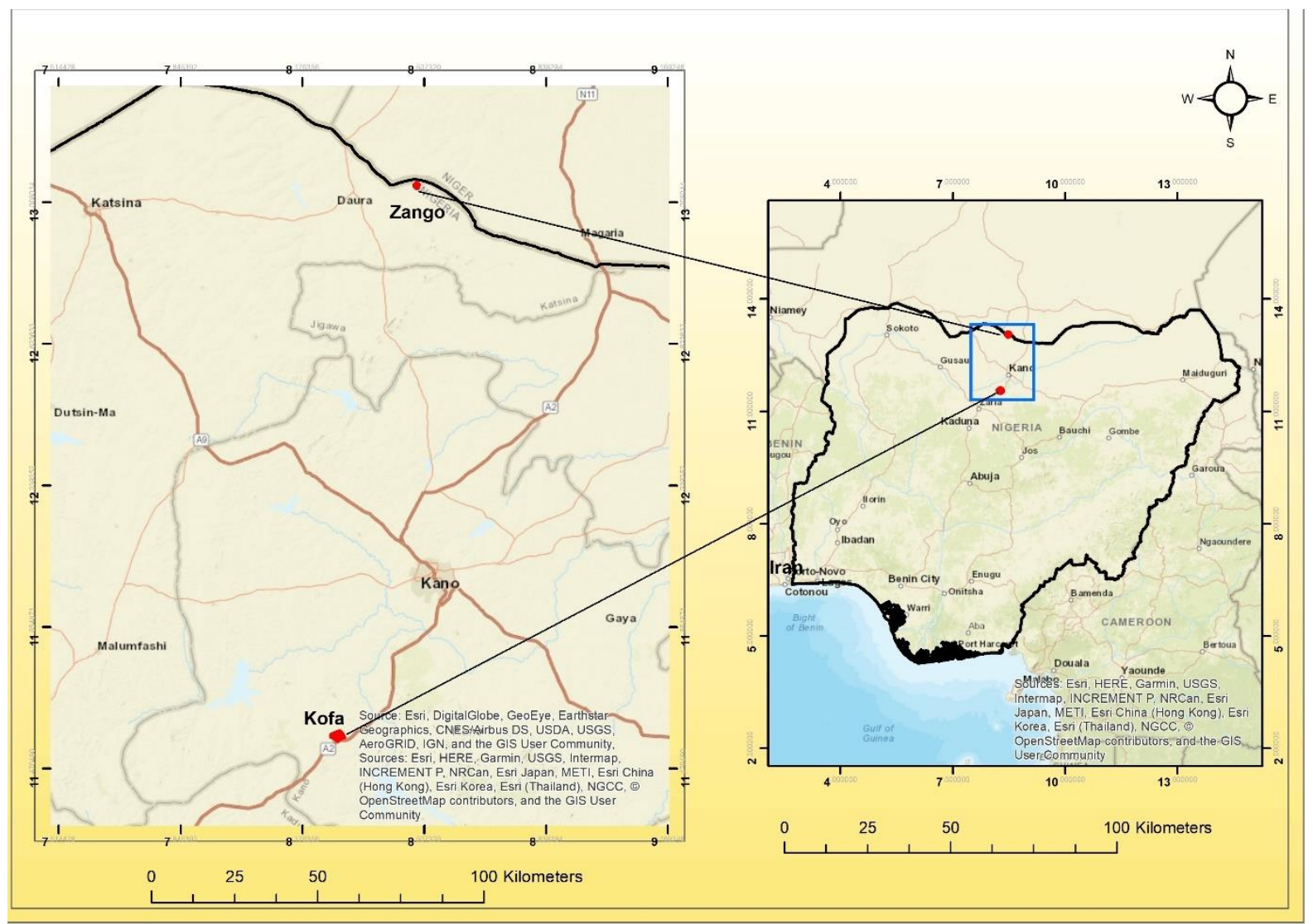

Figure 1. Map of Nigeria showing the two study communities Kofa is on latitude $9^{\circ} 41^{\prime} 14.6^{\prime \prime}$ $\mathrm{N}$ and longitude $7^{\circ} 41^{\prime} 12.4^{\prime \prime} \mathrm{E}$ while Zango lies on latitude $13^{\circ} 03^{\prime} 19.0^{\prime} \mathrm{N}$ and longitude $8^{\circ} 29^{\prime} 17.2 ”$ E. 


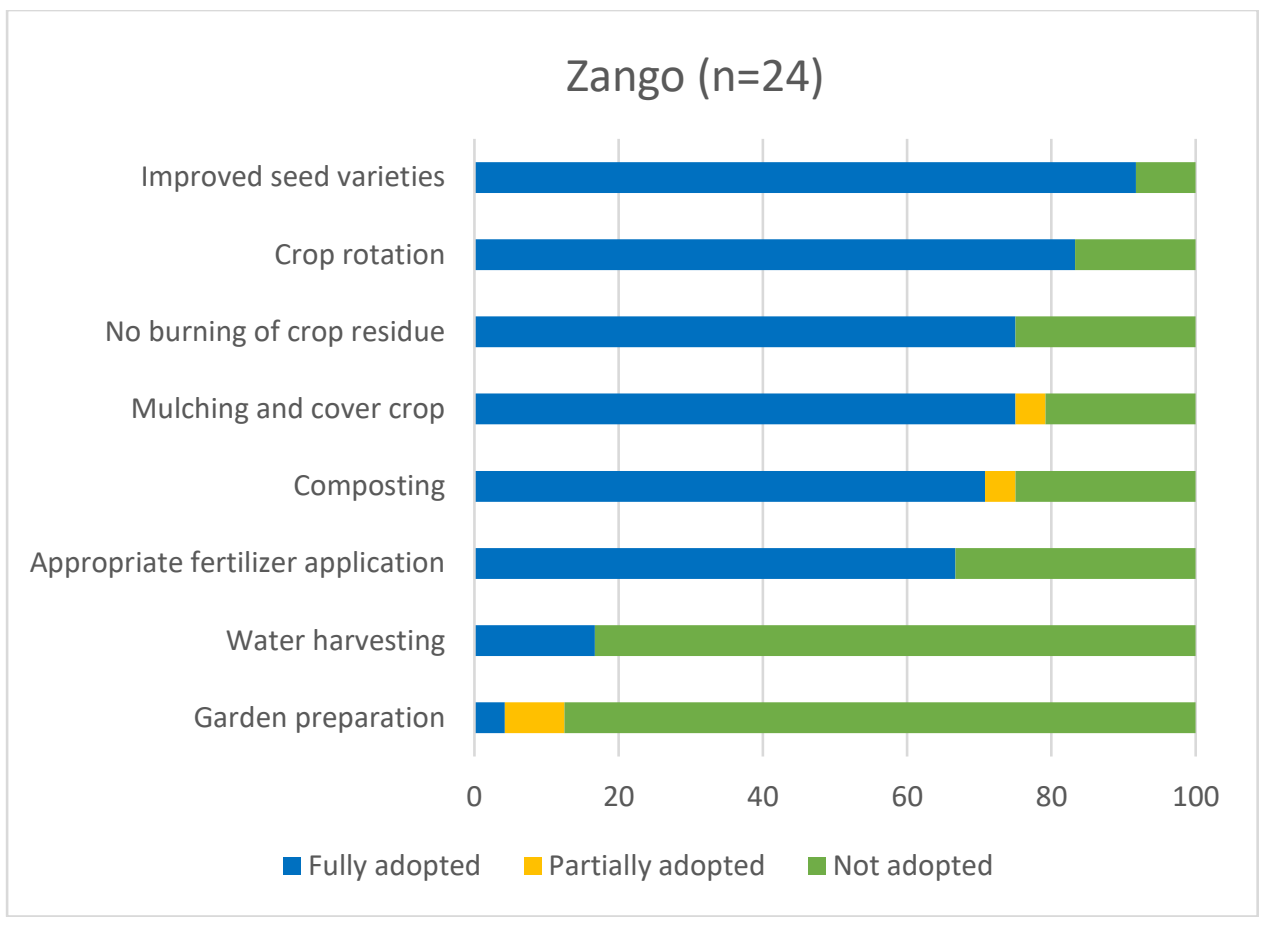

Figure 2. Adoption rates of CSA practices introduced for co-learning in Zango. 


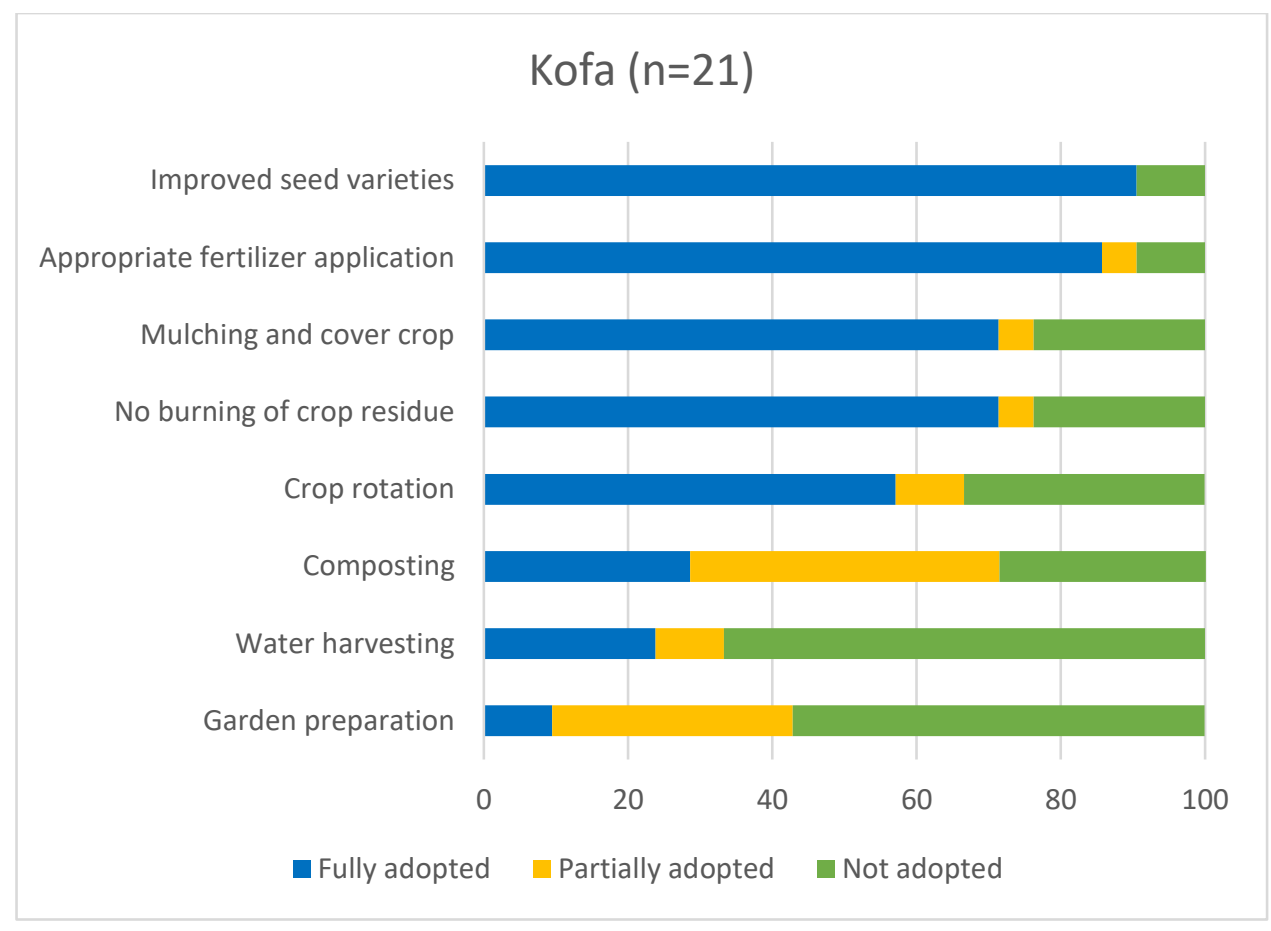

Figure 3. Adoption rates of CSA practices introduced for co-learning in Kofa. 


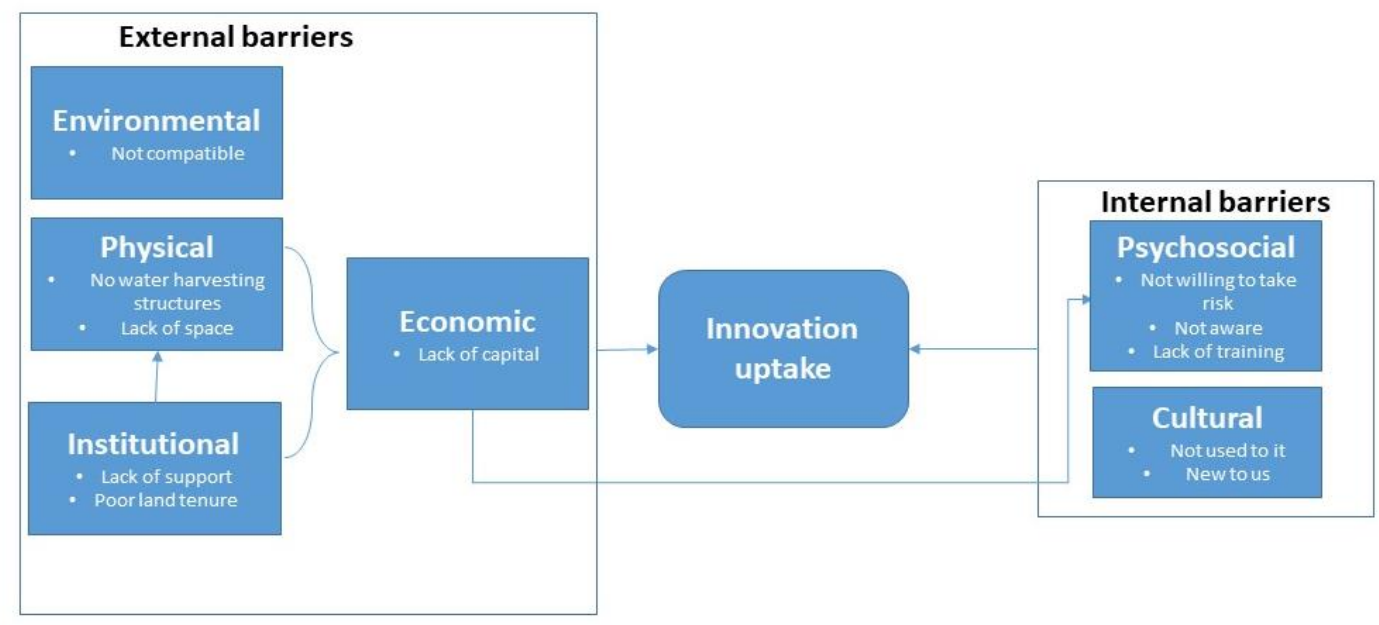

Figure 4. Barriers to adoption in Zango and Kofa (Note: arrow shows the source of influence). Developed with ideas from Meijer et al. (2015). 